\title{
Radiology and histopathology of the bent limbs in campomelic dysplasia: implications in the aetiology of the disease and review of theories
}

\author{
U.E. Pazzaglia ${ }^{1}$ and G. Beluffi ${ }^{2}$ \\ ${ }^{1}$ Orthopedic Clinic, University of Pavia and \\ ${ }^{2}$ Department of Radiology, Pediatric Radiology Section, IRCCS Policlinico San Matteo, Pavia, Italy
}

\begin{abstract}
The study of the bent bones in a case of campomelic dysplasia and a review of the literature suggest a repair process at the site of angulation. A theory that can explain most of the features of the disease is presented; it supposes a damage of the cartilage model at the midshaft, followed by a fracture of the thin bone collar in the earlier stage of ossification of the diaphysis.
\end{abstract}

Following the description by Maroteaux et al. [32] and Bianchine et al. [6] of campomelic dysplasia, many cases have been reported of this usually lethal entity, in which multiple osseous defects (bending of tubular bones is the most striking) and malformations of other organs are associated $[24,31,40,44,46$, $48,49]$.

The genesis of this condition remains uncertain and both an exogenous factor acting in the mother in
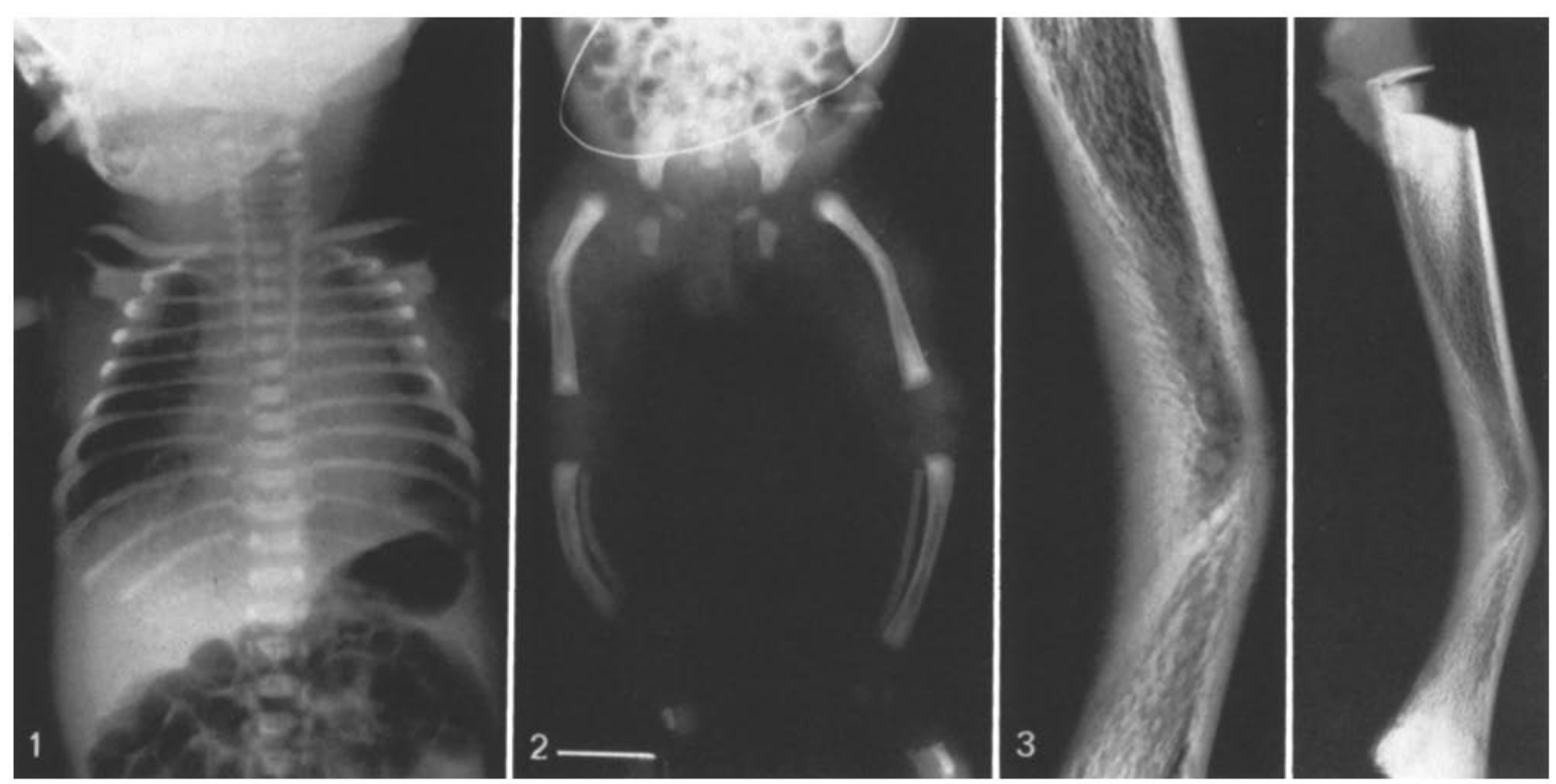

Fig. 1. The chest is bell-shaped, with slender, horizontal ribs and hypoplastic scapulae

Fig. 2. Bowing of the tubular bones of lower limbs; hypoplastic pelvic girdle bones and dislocation of the hips

Fig. 3. X-ray of the tibia after dissection: angulation of the bone between the proximal $2 / 3$ and the distal $1 / 3$. On the concave side the cortex has been replaced by dense bone in which the rayed pattern is evident. Metaphyseal trabeculae are normal 


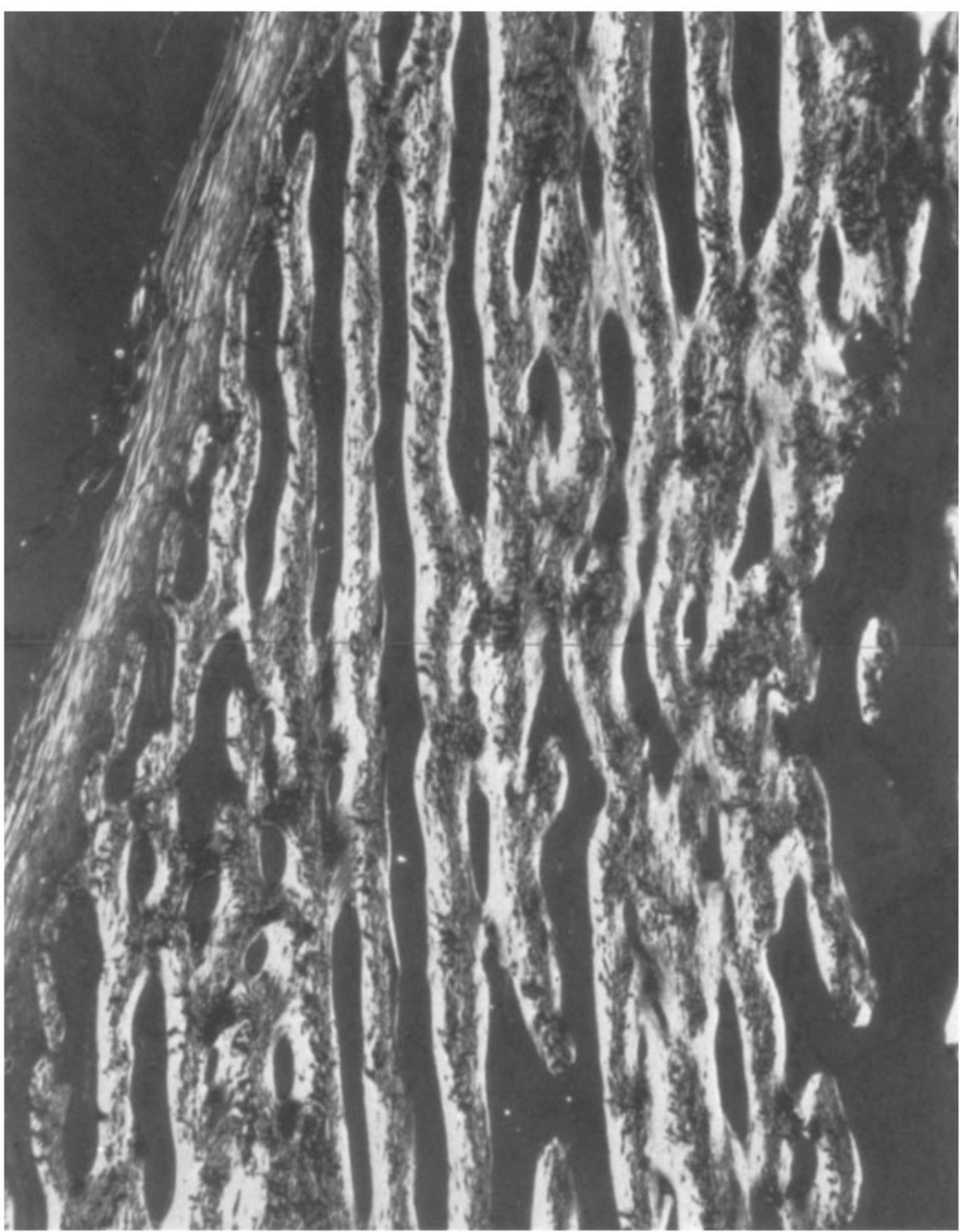

Fig.4. Haematoxylin-eosin $(100 \mathrm{x})$. Polarized light; remodelling of the dense bone on the concave side of angulation, with Haversian canals running in the mass of woven bone the first period of gestation and a genetic factor in the baby have been proposed. In our presentation the histopathological findings of the bent bones of a girl who died at 11 days of age are reported: the study of them led to formulation of ideas about the pathogenesis of the disease.

\section{Case report}

This $3700 \mathrm{-g}$ female infant was born at week 41 of gestation of a 32-year-old mother and a 40 -year-old father.

There is no consanguinity in the kindred; the mother is affected by hyperthyroidism, but there is no record of drug use during gestation. A previous male child was normal. There is no record of abortion. Delivery was spontaneous and natural; the placenta, weighing $500 \mathrm{~g}$ was normal. At birth the infant was dyspneic and cyanotic, requiring mechanical ventilation, and markedly hypotonic. After an initial improvement with spontaneous ventilation, the infant had to be maintained with mechanical ventilation until she died at 11 days of age.

The head circumference was $39 \mathrm{~cm}$, chest circumference $34 \mathrm{~cm}$ and crown-rump length $48 \mathrm{~cm}$. There was hypertelorism, a flat nasal bridge, micrognathia and cleft of the soft palate, low set ears and redundant skin around the neck. The lower limbs were slightly shorter than normal (more so on the right than the left) with anterior bowing of the femora, tibiae and fibulae; a skin dimple over the right tibia; and bilateral talipes equinovarus. External genitalia were normal. The abdomen was swollen; the liver and spleen enlarged.

$\mathrm{X}$-rays showed an enlarged skull and micrognathia. The chest was bell shaped, with slender, horizontal ribs (Fig. 1) and absence of the sternal ossification nuclei. The scapulae were hypoplastic and clavicles had lateral hooks.

The iliac wings were hypoplastic, and the hip joints were dislocated (Fig. 2). The lower limb tubular bones are described in detail in the next section.

Chromosomes were 46, XX.Autopsy, carried out $3 \mathrm{~h}$ after death revealed: atelectasia of both lungs with a small infarction area in the left lower lobe; absence of olfactory bulbs; thymic hypoplasia; enlarged liver and spleen. 

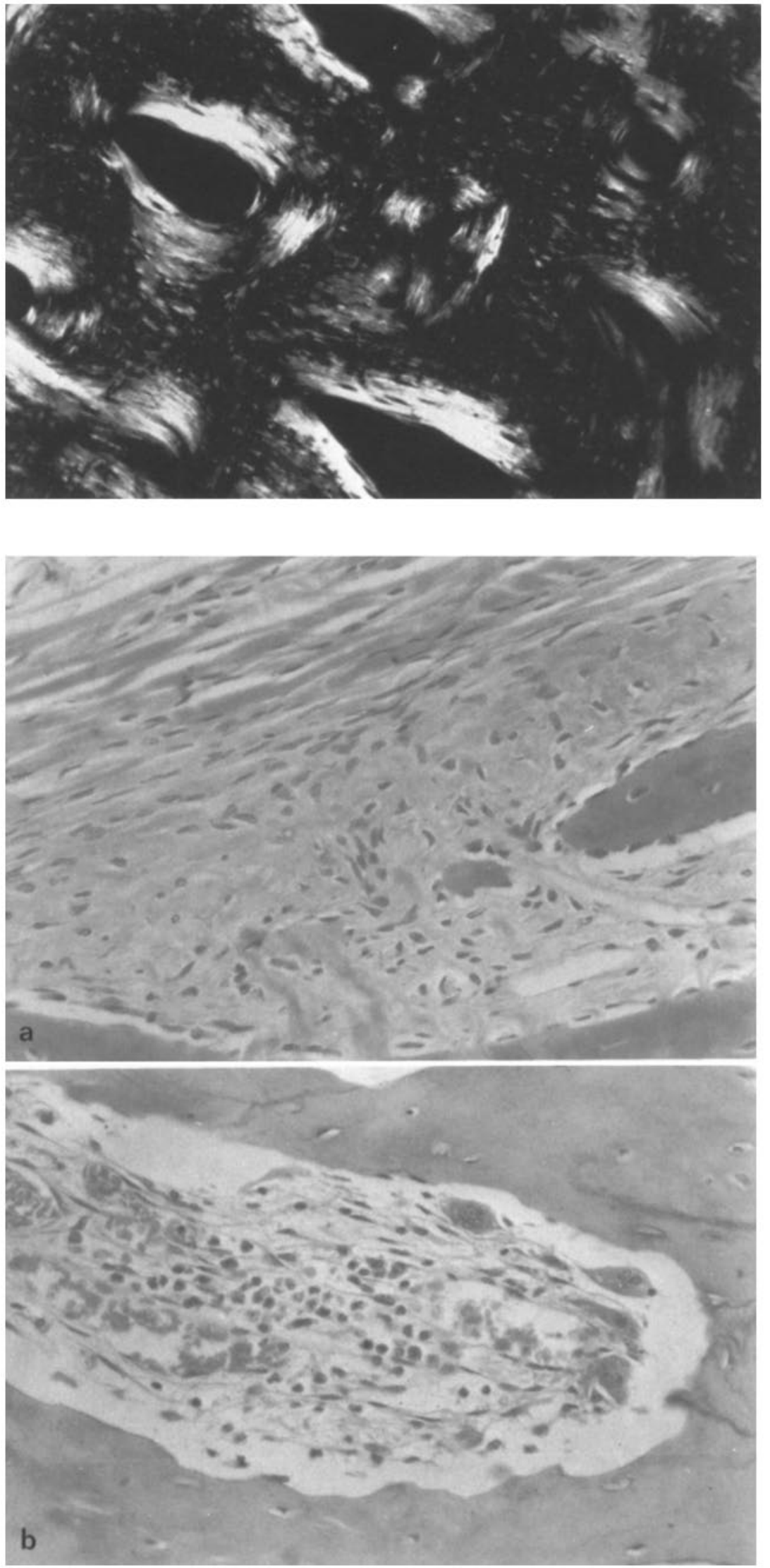

Fig.5. Haematoxylin-eosin $(240 x)$. Polarized light; transverse section of the Haversian canals in the mass of woven bone on the concave side
Fig. 6A and B. Haematoxylin-eosin $(250 \mathrm{x})$. A the origin of Haversian canals beneath the periosteum; B osteoclasts and vessels at the apex of a new Haversian canal 


\section{Material and methods}

The right femur, tibia and fibula were dissected from the soft tissues. A specimen of the tibial, proximal growth plate was immediately fixed in glutaraldehyde and embedded in methacrylate. Undecalcified sections were stained with haematoxylin-eosin and Von Kossa method. Radiographs of the remaining bone specimens were taken and then they were decalcified in a 10\% EDTA solution. After inclusion in paraffin, serial sections in the plane of the bending were prepared and stained with haematoxylin eosin.

\section{Observations}

Radiographs. In the femur there was an angle of $157^{\circ}$ between the axes of the proximal $1 / 3$ and the distal $2 / 3$ of the bone.

Angulation in the tibia and fibula were, respectively, $151^{\circ}$ and $153^{\circ}$, between the proximal $2 / 3$ and the distal $1 / 3$ of the bones. The metaphyseal bone trabeculae, as well as the cortex on the convex side (excepting the site of angulation) were unremarkable. On the concave side the normal cortex had been replaced by broad dense bone in which were thin radiotransparent lines in fan-like arrangement converging toward the apex of the bend (Fig.3).

Histology. The histopathology of the femur, tibia and fibula was the same, and only the tibia will be described in detail.

The epiphysis and growth plate cartilage (and its ossification) were normal. The primary trabeculae, easily recognized because of the central core of cartilage, were normal in their architecture and structure and were undergoing the expected, remodelling.

On the concave side, instead of the normal cortical bone, a less organized woven bone was observed lying between periosteum and the metaphyseal trabeculae. Straight parallel canals, containing blood vessels, ran through it (primary osteons) from the periosteum toward the apex of the cone (Figs. 4 and 6). The surfaces of these canals were the site of remodelling, producing osteonal structures (Fig. 5). This organization was responsible for the rayed pattern observed in X-rays of the specimen.

Periosteal features were unremarkable and no signs of enhanced appositional activity were actually evident.

\section{Discussion}

The histological findings in the bent bones of campomelic dysplasia suggest a repair process with angulation and with new periosteal bone laid down on the concave side and remodelling of the mass of woven bone so formed.

As observed by Roth et al. [39], this process is identical to the healing of malaligned fractures and it is not specific to campomelic dysplasia, since the same thickening of the concave side is observed in other congenital angulation of tubular bones $[9,11$, $14,23,28,35]$. The same histological features can be observed in lower limb experimental bowing obtained in chicken embryos by injecting insulin at the 5 th day $[15,16]$.

A further confirmation of the former statement is given by the only two cases of campomelic dysplasia, who surived [8,32], and by all the other non-lethal cases of congenital bowing of the legs, where a spon- taneous correction of the angulation occurs as the child grows up.

Moreover the growth plate cartilage and the metaphyses look normal and abnormalities described in previous articles $[4,26,29,31]$ do not stand up to critical review, as Austin et al. [3] have already observed.

A theory of the aetiology and pathogenesis of campomelic dysplasia should take account of these observations, but must also satisfactorily explain the features presented constantly in the dysplasia. These may be summarized as follows: level of angulation always between the proximal $1 / 3$ and the distal $2 / 3$ in the femur the opposite in the tibia and fibula; a degree of shortening of the bone, independent from angulation (the so-called short limb variety of campomelic dysplasia is not considered here, because in these cases there are radiographic signs of metaphyseal involvement $[18,21,22,27,51]$; symmetry of lower limb lesions; upper limb tubular bones unaffected or showing only a minor degree of dysplasia; talipes equino-varus; scapula and pelvic girdle bones hypoplastic, with dislocation of the hips; other bone defects (skull, spine, ribs); other organ defect (CNS, respiratory tract, heart, urinary tract, gonads); sporadic cases, but also reported in brothers $[34,42,45$, 47].

The cartilage model of each skeletal element is formed before the end of the embryonic period (8th postovulatory week). The model of tubular bones is sharply defined by the perichondrium; the youngest cells are at the ends, where most of the growth occurs, while the oldest are in the mid-section of the shaft, where, before ossification starts (primary ossification center) they enlarge, their cytoplasm becomes vescicular and the amount of intercellular matrix increases. A bone collar is laid down by the perichondrium (now periosteum) around the midshaft before the matrix calcifies and vascular invasion starts.

The development of the lower limb buds is a little later than the upper and this is observed at all stages, namely, mesenchymal differentiation, chondrification and beginning of ossification [37].

Hypothetically, possible damage to the cells of the midshaft leaving healthy those of the ends of the model) may explain the features observed in campomelic dypslasia. The lesion of the central part of the model is followed by the fracture of the thin bone collar. Since the embryo is surrounded by the amniotic liquid and pressure is transmitted uniformily through liquids, the displacement of the cartilagineous model fragments may be conditioned by the intrinsic tension generated by muscles in the limb or by the postion of the limbs relatively to the body of the 
embryo. In the latter case it is necessary to suppose that all embryos at this stage of development have a remarkably similar position in the uterus because the angulation is always anterior in the tibia and anterolateral in the femur.

The absence of bending of the upper limb bones may be explained by the more advanced developmental stage, with a thicker (and so more resistant to fracture) bone collar, while in an earlier stage the mechanical forces are not strong enough to bend the cartilage model.

In the cartilage of the pelvic girdle and scapula the lesion results in a loss of cells and a hypoplastic mature bone. The same factor may be responsible of the spine, skull and upper respiratory tract cartilage alterations and of other organs malformations.

In the tubular bones the lesion affects the midshaft, while the distal ends of the model grow normally. Since the distal cartilage plate of the femur grows faster than the proximal and vice versa in the tibia, then at birth, when the dysplasia is observed, the apex of the bending is between the proximal $1 / 3$ and the distal $2 / 3$ in the femur and the opposite is seen in the tibia. The loss in length of the bone is therefore due exclusively to the midshaft lesion of the cartilage model.

Two mechanical theories of congenital bowing of the long bones have been presented, one by Middleton [33], the other by Chapple and Davidson [10] and Caffey [9] and by Angle [2]. Both of them presuppose a mechanical force constantly applied to the developing bone. Two points are against these theories: (1) there is a real shortening of the bone; (2) metaphyseal trabeculae are straight and parallel to the axis of the bone and one would expect to find them bent if a constant load were to be applied to the extremities of the bone during growth. The main argument raised by Middleton to support his theory is the constant association of talipes equino-varus to bending; however, there is no evidence that muscular imbalance could be secondary to the bone malformation.

With regard to aetiology, in the first reports attention was addressed to an exogenous factor $[7,19,20$, $29,30,38,43]$, while later it shifted to a genetic defect $[1,5,6,12,13,17,25,26,34,36,47]$.

The pathogensis of the disease and the normal metaphyseal growth plate cartilage favour a factor acting in a limited span of time during the development of the embryo.

Moreover it is interesting to observe that before 1970 few cases which fit in with campomelic dysplasia have been reported $[4,8,50]$, but since then their number increased to over 100 cases. The question of an increasing frequence of the dysplasia has been raised by Segré et al. [41] and by Spranger et al. [43]; since no significant improvement in the basic, diagnostic procedure of campomelic dysplasia (physical examination and radiographs) has been developed, the question of an increasing frequency deserves a careful consideration.

Acknowledgement. The authors wish to thank Dr. P.Tenti, who made available the pathological material for this study, and Dr. P.D. Byers for the useful discussion of the case.

\section{References}

1. Angle CR (1954) Congenital bowing and angulation of the long bones. Pediatrics 13: 257

2. Ameri MR, Alebouyeh M, Amirfeyz M, Ziai M, Rafii MR, Gandjour A (1978) Das kampomele Syndrom. Monatsschr Kinderheilkd 126: 687

3. Austin GE, Gold RH, Mirra JM, Perry S, Moedjono S (1980) Longlimbed campomelic dwarfism. A radiologic and pathologic study. Am J Dis Child 134: 1035

4. Bain AD, Barrett HS (1959) Congenital bowing of the long bones: report of a case. Arch Dis Child 34: 524

5. Beluffi G, Fraccaro M (1982) Genetical and clinical aspects of campomelic dysplasia. In: Skeletal dysplasias, 53. Alan R Liss, New York

6. Bianchine JW, Risenberg HM, Kanderian SS, Harrison HE (1971) Camptomelic dwarfism. Lancet 1: 1017

7. Blessinger GM (1970) Syndrome of multiple asseous deformities. Lancet 2:982

8. Bound JP, Finlay HVL, Rose FC (1952) Congenital anterior angulation of the tibia. Arch Dis Child 27: 179

9. Caffey $J$ (1947) Prenatal bowing and thickening of tubular bones with multiple cutaneous dimples in arms and legs. Am J Dis Child $74: 543$

10. Chapple CC, Davidson DT (1941) A study of the relationship between fetal position and certain congenital deformities. $J$ Pediatr 18: 483

11. Conway TJ (1958) Prenatal bowing and angulation of long bones. Am J Dis Child 95: 305

12. Cremin BJ, Orsmond G, Beighton P (1973) Autosomal recessive inheritance in campomelic dwarfism. Lancet 2: 488

13. Dagna Bricarelli F, Fraccaro M, Lindsten J, Müller U, Baggio P, Doria Lambda Carbone L, Hjerpe A, Lindgren F, Mayerovà $A$, Ringertz $H$, Ritzen $E M$, Rovetta $\mathrm{DC}$, Sicchero $\mathrm{C}$, Wolf $U$ (1981) SeX-reversed XY females with campomelic dysplasia are H-Y negative. Hum Genet 57: 15

14. Dunn AW, Aponte GE (1962) Congenital bowing of the tibia and femur. J Bone Joint Surg 44-A: 737

15. Duraiswami PK (1950) Insulin-induced skeletal abnormalities in developing chickens. Br Med J 2: 384

16. Duraiswami PK (1952) Experimental causation of congenital skeletal defects and its significance in orthopaedic surgery. $\mathrm{J}$ Bone Joint Surg 34-B: 646

17. Fontaine G, Walbaum R, Farriaux JP, Tilmont P, Peuzin F, Delecour M (1980) Le conseil génétique dans la dysplasie campomélique. A propos de deux observations. J Genet Hum 28:267

18. Fryns JP, Annicq P, Ulrix M, Van Den Berghe H (1983) Congenital bowing of the long bone. Acta Paediatr Scand 72:789

19. Gardner LI, Assemany SR, Neu RL (1970) 46, XY female: anti-androgenic effect of oral contraceptive? Lancet 2:667

20. Gardner LI, Assemany SR, Neu RL (1971) Syndrome of multiple osseous defects with pre-tibial dimples. Lancet 2:98 
21. Hall BD, Spranger JW (1979) Familiar congenital bowing with short bones. Radiology 132:611

22. Hall BD, Spranger JW (1980) Congenital bowing of the long bones. A review and phenotype analysis of 13 undiagnosed cases. Eur J Pediatr 133: 131

23. Heyman CH, Herndon CH (1949) Congenital posterior angulation of the tibia. J Bone Joint Surg 31-A: 571

24. Hoefnagel D, Wurster D, Carey D, Harris GJ, Pilliod J (1972) Camptomelic dwarfism, Lancet 1:260

25. Houston CS, Opitz JM, Spranger JW, MacPherson RI, Reed MH, Gilbert EF, Herrmann J, Schinzel A (1983) The campomelic syndrome: review, report of 17 cases, and follow-up on the currently 17 -year-old boy first reported by Maroteaux et al. in 1971. Am J Med Genet 15:3

26. Hovmöller ML, Osuna A, Eklöf O, Fredga K, Hjerpe A, Lindsten J, Ritzén M, Stanescu V, Svenningsen N (1977) Camptomelic dwarfism. A genetically determined mesenchymal disorder combined with sex reversal. Hereditas $86: 51$

27. Khajavi A, Lachman R, Rimoin D, Schimke RN, Dorst J, Handmaker S, Ebbin A, Perreault G (1976) Heterogeneity in the campomelic syndromes: long and short-bones varieties. Radiology 120: 641

28. Kozlowski K, Bützler HO, Galatius-Jensen F, Tulloch A (1978) Syndromes of congenital bowing of the long bones. Pediatr Radiol 7:40

29. Krous HF, Turbeville DF, Altshuler GP (1979) Campomelic syndrome. Possible role of intrauterine viral infection. Terato$\operatorname{logy} 19: 9$

30. Kucera J (1972) Syndrome of multiple osseous defects. Lancet $1: 260$

31. Lee FA, Isaacs H Jr, Strauss J (1972) The "campomelic" syndrome: short life-span dwarfism with respiratory distress, hypotonia, peculiar facies, and multiple skeletal and cartilaginous deformities. Am J Dis Child 124: 485

32. Maroteaux P, Spranger J, Opitz JM, Kučera J, Lowry RB, Schimke RN, Kagan SM (1971) Le syndrome campomélique. Presse Med 25: 1157

33. Middleton DS (1934) Studies on prenatal lesions of striated muscles as a cause of congenital deformity. Edinburgh Med $\mathrm{J}$ 41: 401

34. Mojedono SJ, Crandal BF, Sparkes RS, Feldman GM, Austin GE, Perry $S(1980)$ The campomelic syndrome in a singleton and monozygotic twins. Clin Genet 18:397

35. Newell RLM, Durbin FC (1976) The aetiology of congenital angulation of tubular bones with constriction of the medullary canal and its relationship to congenital pseudoarthrosis. J Bone Joint Surg 58-B: 444

36. Noyal P, Vermeulin C, Hibon D, Meck JM (1982) La dysplasie campomélique. Un cas de survie au-delà de 4 ans. Arch Fr Pediatr 39: 621
37. O'Rahilly R, Gardner E (1976) The embriology of bone and bones. In: Ackerman LV, Spjnt HJ, Abell MR (eds) Bones and joints. Williams \& Wilkins, Baltimore, p 1

38. Papp Z, Gardo S (1971) Effect of exogenous hormons on the fetus. Lancet 1:753

39. Roth SI, Jimenez JF, Husted S, Seibert JJ, Haynes DW (1982) The histopathology of camptomelia (bent limbs). A dyscondrogenesis. Clin Orthop 167: 152

40. Schmickel RD, Heidelbergere KP, Poznanski AK (1973) The campomelique syndrome. J Pediatr 82: 299

41. Segré A, Beluffi G, Peretti G (1978) Camptomelic syndrome. A rare type of congenital dwarfism associated with skeletal and other abnormalities. Ital J Orthop Traumatol 4:237

42. Shafai T, Schwartz L (1976) Camptomelic syndrome in siblings. J Pediatr 89: 512

43. Spranger J, Langer LO, Maroteaux $P$ (1970) Increasing frequency of a syndrome osseous defects? Lancet 2:716

44. Storer J, Grossman H (1974) The campomelic syndrome. Radiology 111: 673

45. Stüve A, Wiedemann H-R (1971) Congenital bowing of the long bones in two sisters. Lancet 2:495

46. Tokita N, Chandra-Sekhar HK, Daly JF, Becker MH, Aleksic $\mathrm{S}$ (1979) The campomelic syndrome. Temporal bone histopathologic features and otolaryngologic manifestations. Arch Otolaryngol 105: 449

47. Thurmon TF, De Fraites EB, Anderson EE (1973) Familiar camptomelic dwarfism. J Pediatr 83: 841

48. Wagner EJ, Hawey PJ (1983) Case report 230. Skeletal Radiol $9: 283$

49. Weiner DS, Benfield $G$, Robinson H (1976) Camptomelic dwarfism. Report of a case and review of the salient features. Clin Orthop 116: 29

50. Williams ER (1943) Two congenital deformities of the tibia: congenital angulatione and congenital pseudoarthrosis. $\mathrm{Br} \mathrm{J}$ Radiol 16: 371

51. Winter R, Rosenkranz W, Hofmann $H$, Zierler $H$, Becker $H$, Borkenstein $M$ (1985) Prenatal diagnosis of campomelic dysplasia by ultrasonography. Prenat Diagn 5:1

Received: 18 March 1986; accepted: 10 May 1986

Dr. U.E. Pazzaglia

Clinica Ortopedica

dell' University di Pavia

Via Taramelli

I-27100 Pavia

Italy 